\title{
Synthesis, structure and properties of poly(ester-urethane)s obtained using bio-based and petrochemical 1,3-propanediol and 1,4-butanediol
}

\author{
Janusz Datta $^{1}$ (D) Paulina Kasprzyk ${ }^{1} \cdot$ Kamila Błażek $^{1} \cdot$ Marcin Włoch $^{1}$
}

Received: 1 December 2016/Accepted: 27 June 2017/Published online: 10 July 2017

(c) The Author(s) 2017. This article is an open access publication

\begin{abstract}
In this paper, the poly(ester-urethane)s obtained using petrochemical and bio-based chain extenders were prepared and characterized. The influence of glycols' origin on the chemical structure, mechanical and thermal properties of the prepared polyurethanes was studied. The materials were synthesized by prepolymer method. The first step involved the reaction of $\alpha, \omega$-dihydroxy(ethylenebutylene adipate) (POLIOS 55/20) with 4,4'-diphenylmethane diisocyanate (MDI). In the next step, obtained prepolymer terminated with isocyanate group was extended using 1,3-propanediol and 1,4-butanediol at three different molar ratios of NCO group (presented in prepolymer chains) to $\mathrm{OH}$ groups (presented in chain extender structure), i.e., $0.95,1.0$ and 1.05 . The results showed that applying the different types (diversified chemical structure and origin) of glycols results in obtaining materials with diversified mechanical properties and slight different thermal stabilities. The results of Fourier transform infrared spectroscopy showed that the chemical structure of the obtained polyurethanes was not affected by the presence of glycols with the same chemical structure and different origins (petrochemical and bio-based nature).
\end{abstract}

Keywords Poly(ester-urethane)s · Chemical structure · Thermal stability $\cdot$ Mechanical properties $\cdot$ Bio-based glycols $\cdot$ Petrochemical-based glycols

Janusz Datta

janusz.datta@pg.gda.pl

1 Department of Polymers Technology, Faculty of Chemistry, Gdańsk University of Technology, G. Narutowicza Str. 11/12, 80-233 Gdańsk, Poland

\section{Introduction}

Polyurethanes (PUs) are significant group of the polymers, which possess a lot of unique properties, which creates a possibility to use them in different branches of the industry, e.g., automotive, medicine, electronic, construction, building and packaging. PUs can be obtained as a foams [1], elastomers [2, 3], thermoplastics [4], coatings [5], as well as fibers $[6,7]$. It is also possible to use polyurethanes as a component for preparing polymer composites [8] or blends $[9,10]$. Generally, the synthesis of PUs is carried out using one- or two-step method. These reactions are frequently conducted using non-renewable and petroleumbased feedstock, like aliphatic [e.g., hexamethylene diisocyanate (HDI), 4,4'-methylene dicyclohexyl diisocyanate (HMDI)] or aromatic diisocyanates [e.g., 4,4'-methylene diphenyl diisocyanate (MDI), toluene diisocyanate (TDI)], macrodiols [e.g., poly(tetrahydrofuran) (PTHF), poly(ethylene glycol) (PEG)] and low molecular weight chain extenders (e.g., 1,4-butanediol or 1,3-propanediol) [11-14]. Polyurethanes are consisted of hard segments containing isocyanates as well as chain extender moieties and also soft segments comprising polyols moieties. The actual trends of green chemistry are connected with the replacing of petrochemical-based chemicals by bio-based and renewable feedstock. The increasing interest in the area of bio-based substances (e.g., polyols [1, 2, 15, 16], chain extenders [17-20] and diisocyanates [21, 22]) used as a components in the synthesis of polyurethanes is observed. According to the literature, the non-isocyanates polyurethanes synthesized using natural resources (e.g., vegetable oils, bio-based diamines, fatty acids and glycerol) are also known [23, 24].

Chain extenders are a low molecular weight compounds, for example diamines or diols. These chemicals have 
mainly impact on the mechanical and physicochemical properties of the obtained polyurethanes such as stiffness or hardness [12], density of hydrogen bonds as well as molecular weight of final materials $[11,25]$. The chemical structure and the length of the chain extenders used in the synthesis modify, for example, the chemical structure and the weight ratio of the hard segments to the soft segment, and by this way chain extenders influence on the performance of the obtained polyurethanes [26]. Blackwell et al. [27] and Prisacariu et al. [26] demonstrated that the performance of the polyurethane elastomers depends on number of methylene units in the chemical structure of diols used as chain extenders. On the basis of these results, the most advantageous properties, especially mechanical effects, are obtained using diols with even number of methylene groups (for example, 1,4-butanediol or 1,8octanediol).

From the environmental point of view, it is important to replace substrates derived from non-renewable resources by bio-based substances. Over the past few years, novel bio-glycols obtained from natural feedstocks were proposed as components for the synthesis of polymers, for example Zemea ${ }^{\circledR}$ propanediol (DuPont Tate \& Lyle BioProducts) [28, 29], Susterra ${ }^{\circledR}$ propanediol (DuPont Tate \& Lyle BioProducts) [18, 29-31], 1,3-propanediol from sorghum [32], bio-butanediol from bio-succinic acid [33], 1,4-butanediol realized by using Genomatica's GENO $\mathrm{BDO}^{\mathrm{TM}}$ process [34], 1,4-butanediol from glucose syrup [35], 1,3-propanediol from crude glycerol [36] and others.

The polyurethanes for industrial applications are synthesized using 1,4-butanediol, which is obtained from petroleum-based resources using different types of processes, which include hydrogenation of maleic anhydride or an aqueous maleic acid, Reppe process based on acetylene and formaldehyde, acetoxylation or epoxidation of butadiene, hydroformylation of allyl alcohol as a next stage after isomerization of propylene oxide [37-40]. The synthesis of petrochemical 1,3-propanediol is connected with two main types of reaction, i.e., hydroformylation of ethylene oxide and hydration of acrolein [32, 36, 38] (Fig. 1).
Obele et al. [32] performed synthesis of 1,3-propanediol from which starch was prepared from white sorghum. Dual enzyme technique was used to convert glucose from sorghum into glycerol, which was subsequently turned to final product using bacteria mixture (Escherichia coli and Klebsiella). The obtained compounds were compared to maize-based PDO. Considering the results, the properties for both types of bio-based PDO are similar. Moreover, the sorghum-based PDO has comparable purity to the petrochemical-based PDO.

DuPont Company [41] proposed using of Susterra ${ }^{\circledR} 1,3-$ propanediol as a chain extender for the synthesis of the thermoplastic polyurethane's. Susterra ${ }^{\circledR}$ is a completely bio-based diol obtained by biotechnological process from corn sugar. Rashmi et al. [18] demonstrated that the replacement of petroleum-based chain extenders by biobased one like Susterra ${ }^{\circledR}$ was not reduced the properties of obtained materials, e.g., solubility, thermal and mechanical properties. Another bio-derived propanediol produced by DuPont Tate \& Lyle BioProducts is Zemea ${ }^{\circledR}$, which is also obtained in the fermentation process of the corn glucose. Manufacturer proposed this product as an alternative for the petrochemical-based compounds (e.g., butylene glycol or propylene glycol) in the area of personal care [42].

Furthermore, 1,3-propanediol can be produced by biotechnological routes from crude glycerol obtained as a by-product in the biodiesel production. Mentioned process is based on microorganisms, for example Clostridium butyricum, Clostridium acetobutylicum and Klebsiella pneumonia [36].

In accordance with the synthesis of bio-based butanediol, BASF and Genomatica developed innovative method using sugars and genetically modified strain of E. coli bacteria [34]. Johnson Matthey Company and Myriant Corporation are offered a process to produce entirely renewable bio-butanediol. Synthesis is comprised of two main steps, i.e., the conversion of sugar into bio-succinic acid using Myriant's process and the transformation of obtained acid into bio-butanediol [33].

The environmental benefits of bio-glycols are very important from the 'green chemistry' point of view, but the

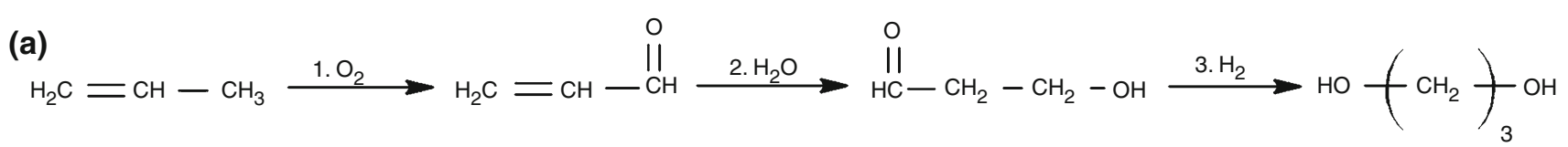

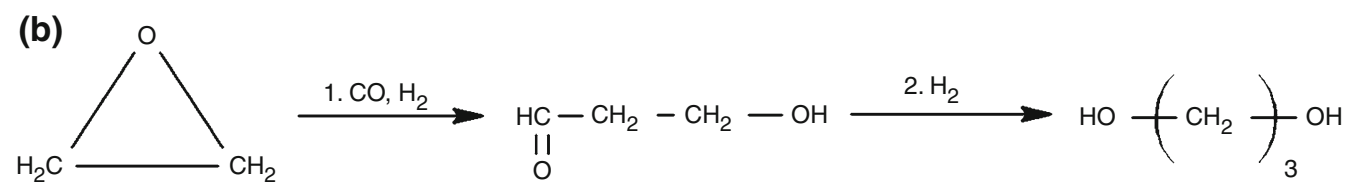

Fig. 1 Three- and two-step synthesis process of petrochemical 1,3-propanediol 


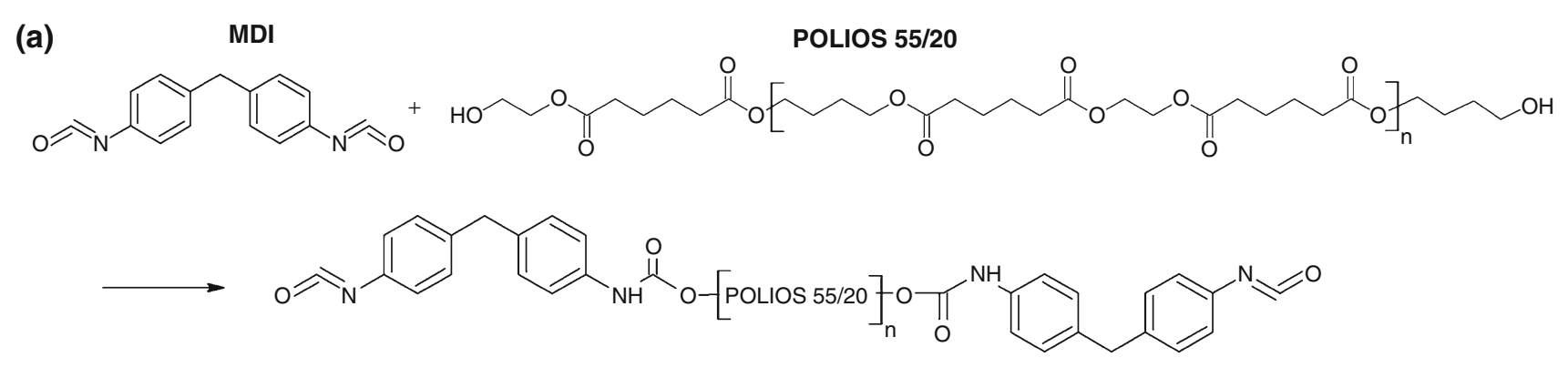

(b)

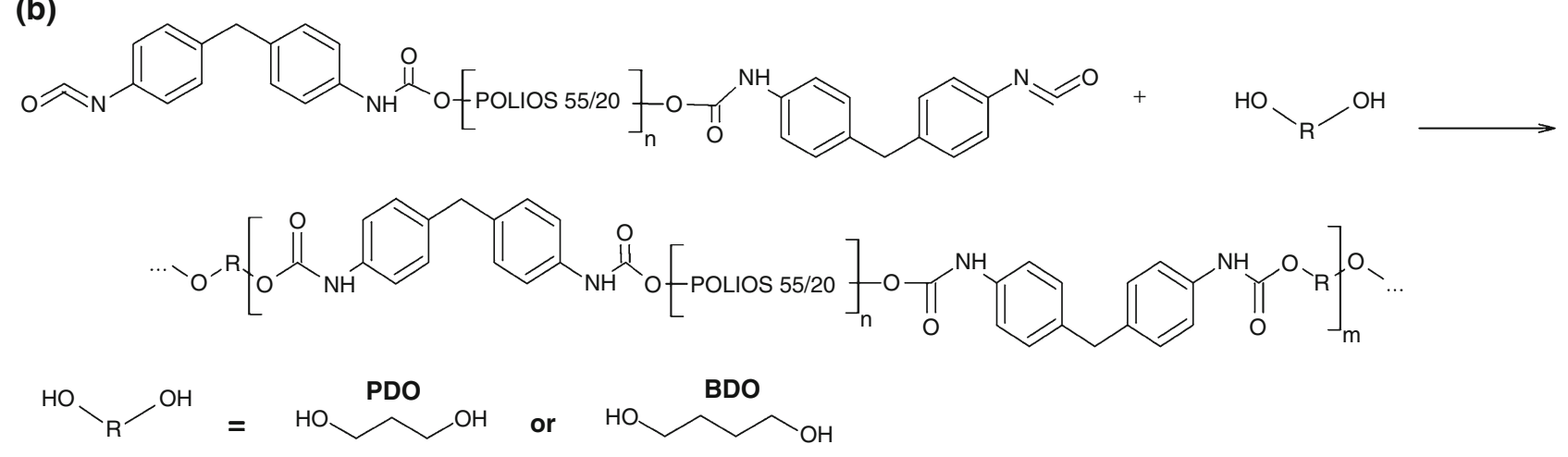

Fig. 2 Synthesis of poly(ester-urethane)s by the prepolymer method: a synthesis of ester-urethane prepolymer by the reaction of diisocyanate MDI and polyol POLIOS 55/20, b extending of ester-urethane prepolymer chains using bio-based and petroleum-based diols

influence of the bio-glycols on the chemical structure and performance of the polymers synthesized using them should be investigated in detail. The petrochemical and biotechnological processes are different in several points, but the final products of both processes can be contaminated by several chemical compounds, for example intermediates or by-products. This contamination can significantly influence on the chemical structure and properties of polyurethanes, and this is resulted from the lower mass of chain extenders in comparison with the mass of polyols or isocyanates used during the synthesis of PUs.

According to the literature, the bio-based glycols can contain contaminations like 2,3-butanediol, lactic acid, acetic acid, ethanol, succinic acid 1,4-butanediol monoacetate, 4-hydroxybutyraldehyde and another ketones and aldehydes, enzymes and inorganic compounds [43-45].

In this work, the influence of different types (obtained from bio-based or petrochemical sources) of 1,3-propanediol and 1,4-butanediol on the chemical structure, dynamic mechanical properties (i.e., storage modulus, loss modulus and tan delta), mechanical properties (i.e., tensile properties, hardness and rebound resilience) and thermal stability was studied. It was found that chain extenders from different origins result in obtaining materials with the similar mechanical and thermal properties.

\section{Experimental}

\section{Materials}

The ester-based polyol, i.e., $\alpha, \omega$-dihydroxy(ethylene-butylene adipate) (POLIOS 55/20, $M_{\mathrm{n}}=2000 \mathrm{~g} \mathrm{~mol}^{-1}$ ) was purchased from Purinova, Poland. The aromatic diisocyanate, i.e., 4,4'-diphenylmethane diisocyanate (MDI), was received from BorsodChem, Hungary (ONGRONAT ${ }^{\circledR}$ 3000 , viscosity $10 \mathrm{mPa} \mathrm{s}$ at $43{ }^{\circ} \mathrm{C}, \mathrm{NCO}$ content min. 33.4 mass $\%$, density $1.18 \mathrm{~g} \mathrm{~cm}^{-3}$ at $43{ }^{\circ} \mathrm{C}$ ). Petrochemical-based chain extenders, i.e., 1,3-propanediol (purity $98 \%$, density $1.06 \mathrm{~g} \mathrm{~cm}^{-3}$ at $20{ }^{\circ} \mathrm{C}$, viscosity $37 \mathrm{mPa}$ s at $25^{\circ} \mathrm{C}$ ) and 1,4-butanediol (purity 99\%, density $1.02 \mathrm{~g} \mathrm{~cm}^{-3}$ at $25^{\circ} \mathrm{C}$, viscosity $69 \mathrm{mPa} \mathrm{s}$ at $20^{\circ} \mathrm{C}$ ), were obtained from Sigma-Aldrich and Brenntag, respectively. Two bio-based glycols were used in this study, i.e., 1,3propanediol $\quad$ (Susterra $^{\circledR}$, purity $99.98 \%$, density $1.04 \mathrm{~g} \mathrm{~cm}^{-3}$ at $25{ }^{\circ} \mathrm{C}$, viscosity $36 \mathrm{mPa}$ s at $25^{\circ} \mathrm{C}$ ) kindly provided by DuPont Tate \& Lyle and 1,4-butanediol kindly provided by BASF (purity $99.5 \%$, density $1.02 \mathrm{~g} \mathrm{~cm}^{-3}$ at $20{ }^{\circ} \mathrm{C}$, viscosity $70 \mathrm{mPas}$ at $25^{\circ} \mathrm{C}$ ). 1,4-diazabicyclo[2.2.2] octane (DABCO) was received from SigmaAldrich and was used as a catalyst in the reaction of isocyanate groups and hydroxyl groups. 


\section{Synthesis of thermoplastic polyurethanes}

The poly(ester-urethane)s were synthesized by the two-step method, also called prepolymer method (Fig. 2). In the first step, prepolymer was synthesized by the reaction of $\alpha, \omega$ dihydroxy(ethylene-butylene adipate) POLIOS 55/20 and $4,4^{\prime}$-diphenylmethane diisocyanate (MDI) at $85{ }^{\circ} \mathrm{C}$ for $4 \mathrm{~h}$. Prepolymer chains were terminated by isocyanate groups, and percentage content of the isocyanate groups was equal to $6 \%$ (measurements were taken according to the ISO 14896 standard). In the second step, obtained prepolymer chains were extended using 1,3-propanediol or 1,4-butanediol with 0.3 mass $\%$ of DABCO, which was used as a catalyst. The poly(ester-urethane)s were synthesized at three different molar ratios $[\mathrm{NCO}] /[\mathrm{OH}]$ equal $0.95,1.0$ and 1.05 during the chains' extending step. Obtained PUs were cured at $100{ }^{\circ} \mathrm{C}$ for $24 \mathrm{~h}$. The codes of the obtained materials and their meaning are presented in Table 1.

\section{Testing methods}

Confirmation of the chemical structure of prepared thermoplastic polyurethanes was investigated by means of Fourier Transform Infrared Spectroscopy (FTIR) using Nicolet FTIR 8700 spectrophotometer (Thermo Electron Co.). The spectra were recorded in the range of wave numbers from 500 to $4500 \mathrm{~cm}^{-1}$ with a resolution $4 \mathrm{~cm}^{-1}$ at room temperature. For each spectrum, 64 scans were taken.

Table 1 Codes of obtained poly(ester-urethane)s and description of their meaning

\begin{tabular}{lll}
\hline Code of material & Chain extender & $\begin{array}{l}\text { Molar ratio } \\
{[\mathrm{NCO}] /[\mathrm{OH}]} \\
\text { during } \\
\text { extending of } \\
\text { prepolymer } \\
\text { chains }\end{array}$ \\
\hline PU-Bio-BDO 0.95 & Bio-based 1,4-butanediol & 0.95 \\
PU-Bio-BDO 1.0 & & 1.0 \\
PU-Bio-BDO 1.05 & & 1.05 \\
PU-BDO 0.95 & Petrochemical-based & 0.95 \\
PU-BDO 1.0 & 1,4-butanediol & 1.0 \\
PU-BDO 1.05 & & 1.05 \\
PU-Bio-PDO 0.95 & Bio-based 1,3-propanediol & 0.95 \\
PU-Bio-PDO 1.0 & & 1.0 \\
PU-Bio-PDO 1.05 & & 1.05 \\
PU-PDO 0.95 & Petrochemical-based & 0.95 \\
PU-PDO 1.0 & 1,3-propanediol & 1.0 \\
PU-PDO 1.05 & & 1.05 \\
\hline
\end{tabular}

Chemical structure of petrochemical and bio-based glycols was investigated by Hydrogen Nuclear Magnetic Resonance Spectroscopy $\left({ }^{1} H\right.$ NMR $)$. The ${ }^{1} \mathrm{H}$ NMR spectra were recorded at the room temperature using a Varian Mercury Vx spectrometer operating at frequency of $400 \mathrm{MHz}$, by applying $\left(\mathrm{CD}_{3}\right)_{2} \mathrm{SO}$ as a solvent. The measurements were taken in the Department of Inorganic Chemistry at Gdansk University of Technology.

The presence of contaminations in the used petrochemical and bio-based glycols was investigated by means of Gas Chromatography combined with a Mass Spectrometer $(G C-M S)$. Analyses were performed using an HP 5890 (Hewlett-Packard, Palo Alto, California) gas chromatograph equipped with FID detector. As a chromatographic column, J\&W DB-1 $(30 \mathrm{~m} \times 0.32 \mathrm{~mm} ; 5 \mu \mathrm{L})$ was applied.

Atomic Force Microscopy (AFM) was used to analyze the surface morphology of selected poly(ester-urethane)s. The measurements were taken using AFM Nanosurf EasyScan II microscope in tapping mode. The AFM micrographs were processed in Gwyddion program. The

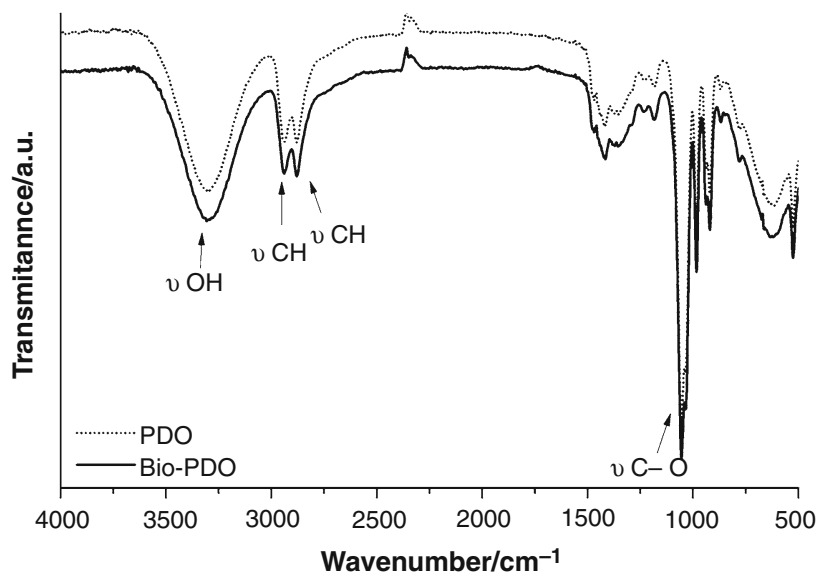

Fig. 3 FTIR spectra of bio-based and petrochemical 1,3-propanediol

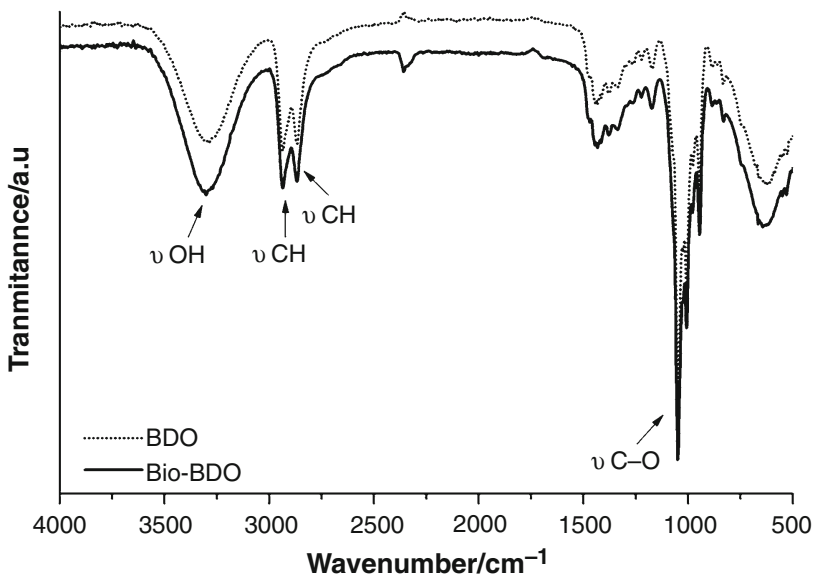

Fig. 4 FTIR spectra of bio-based and petrochemical 1,4-butanediol 
Fig. $5{ }^{1} \mathrm{H}$ NMR spectra of biobased and petrochemical 1,3propanediol

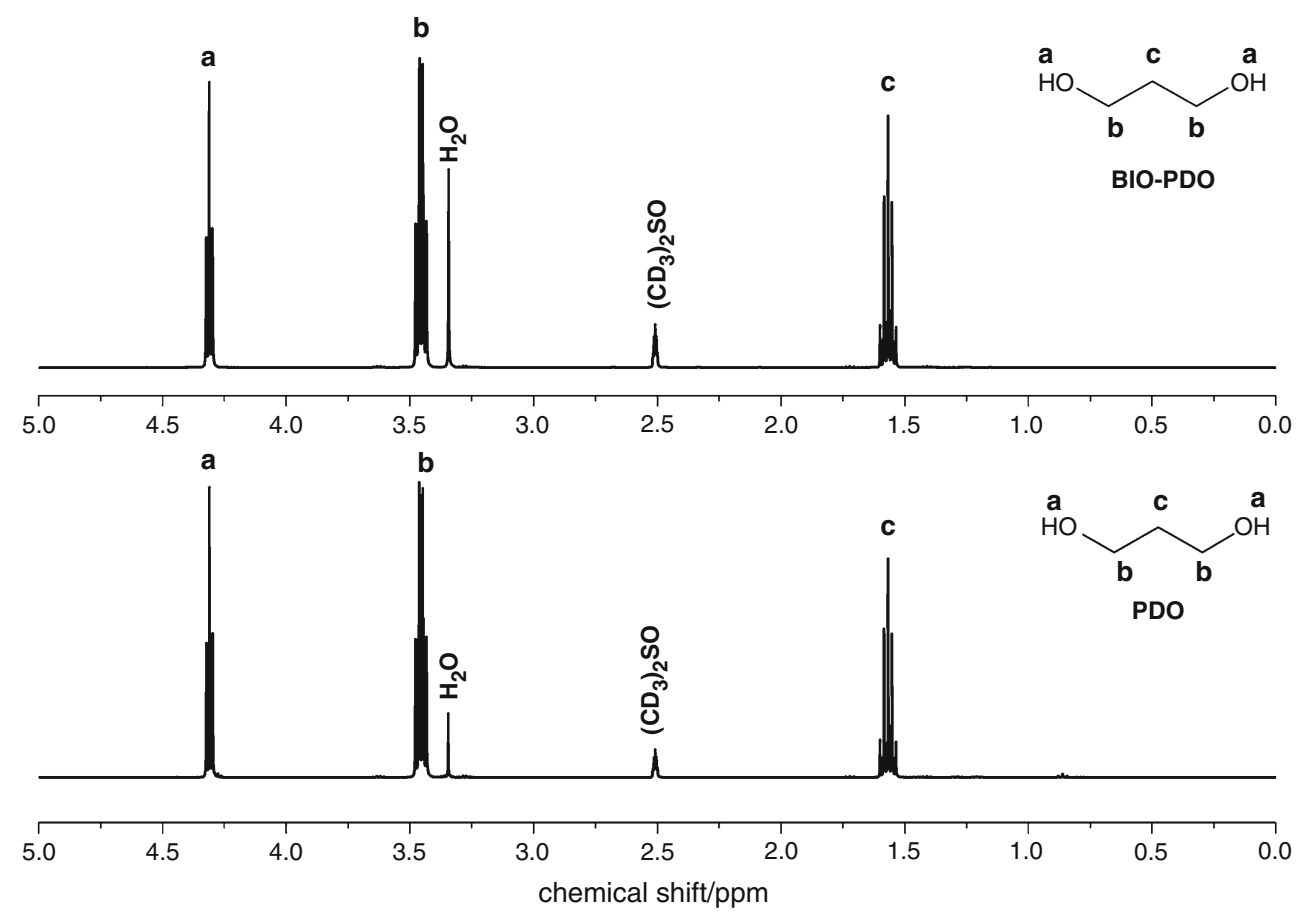

Fig. $6{ }^{1} \mathrm{H}$ NMR spectra of biobased and petrochemical 1,4butanediol

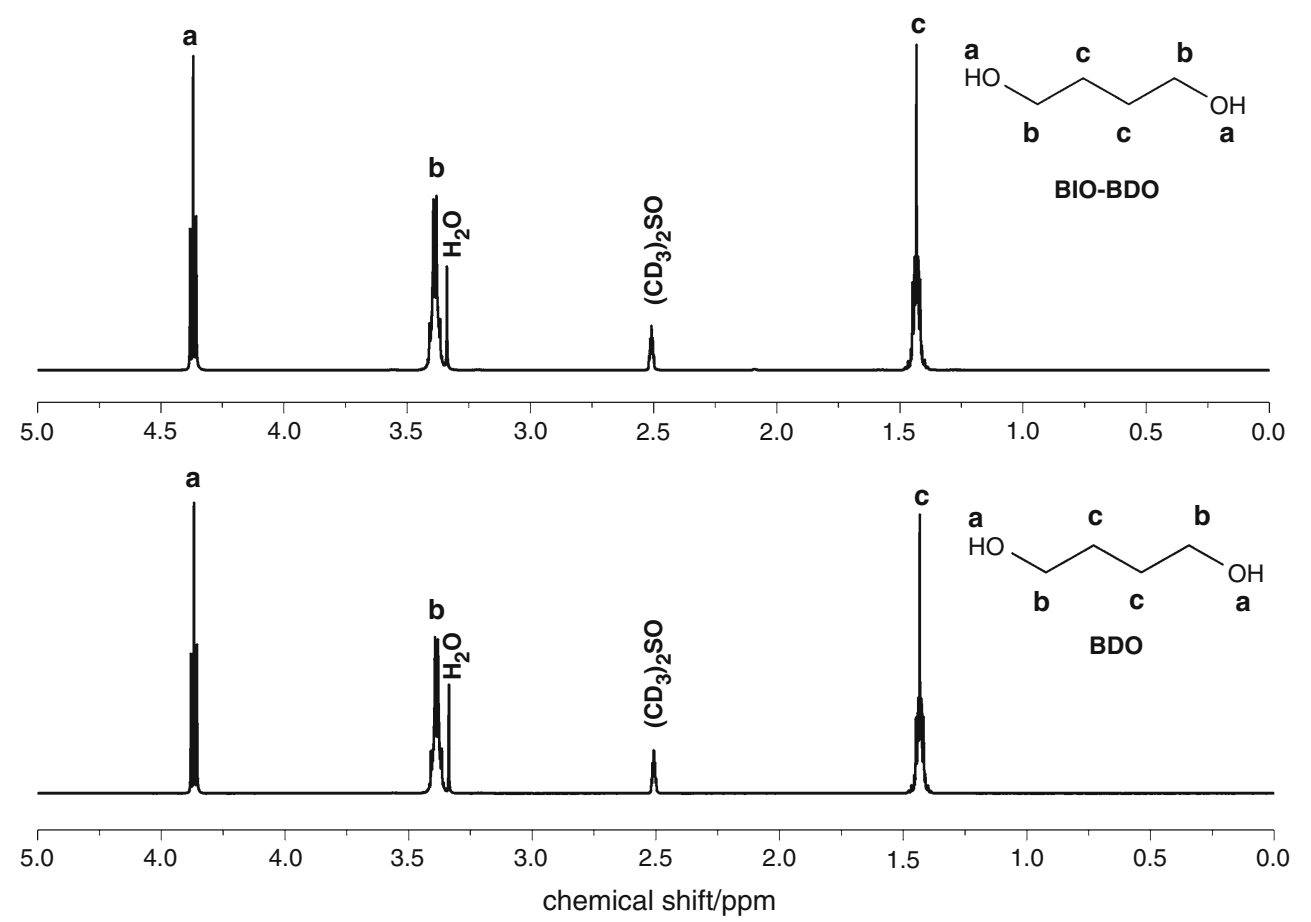

measurements were taken in the Faculty of Applied Physics and Mathematics at Gdańsk University of Technology.

Tensile properties, i.e., tensile strength and elongation at break, were investigated using an universal testing machine Zwick/Roell Z020 at room temperature, according to ISO 37. The dumbbell-shaped samples of standard dimensions (length $115 \mathrm{~mm}$ ) were also tested at a crosshead speed of $100 \mathrm{~mm} \mathrm{~min}^{-1}$. The original gauge length was equal to $25 \mathrm{~mm}, 6 \mathrm{~mm}$ wide and $2 \mathrm{~mm}$ thick.

Hardness was measured according to ISO 868 standard using an electronic shore type A and D durometer, and presented results are averaged from random ten points in one specimen.

Rebound resilience was measured according to ISO 4662 standard. Measurements were taken using a Schob 


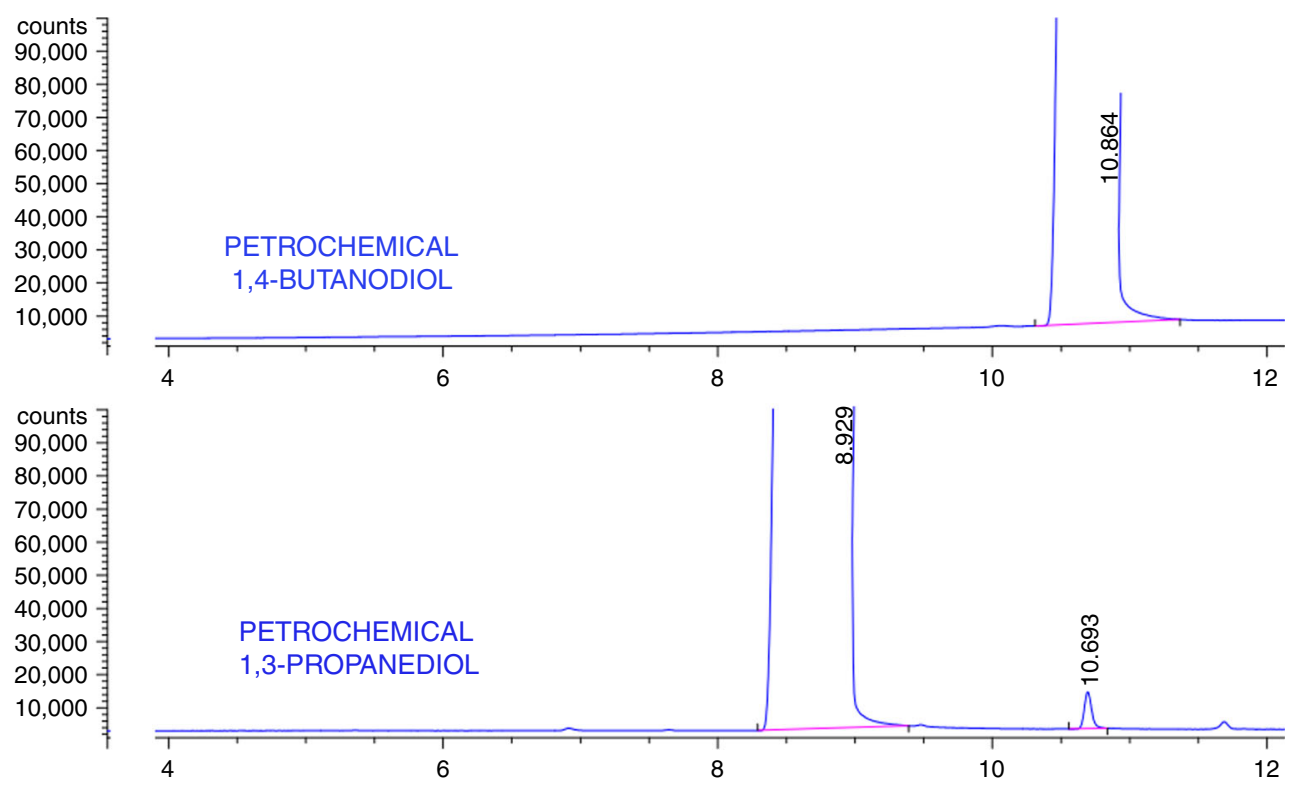

Fig. 7 GC chromatograms obtained during the chromatographic analysis of petrochemical 1,3-propanediol and 1,4-butanediol

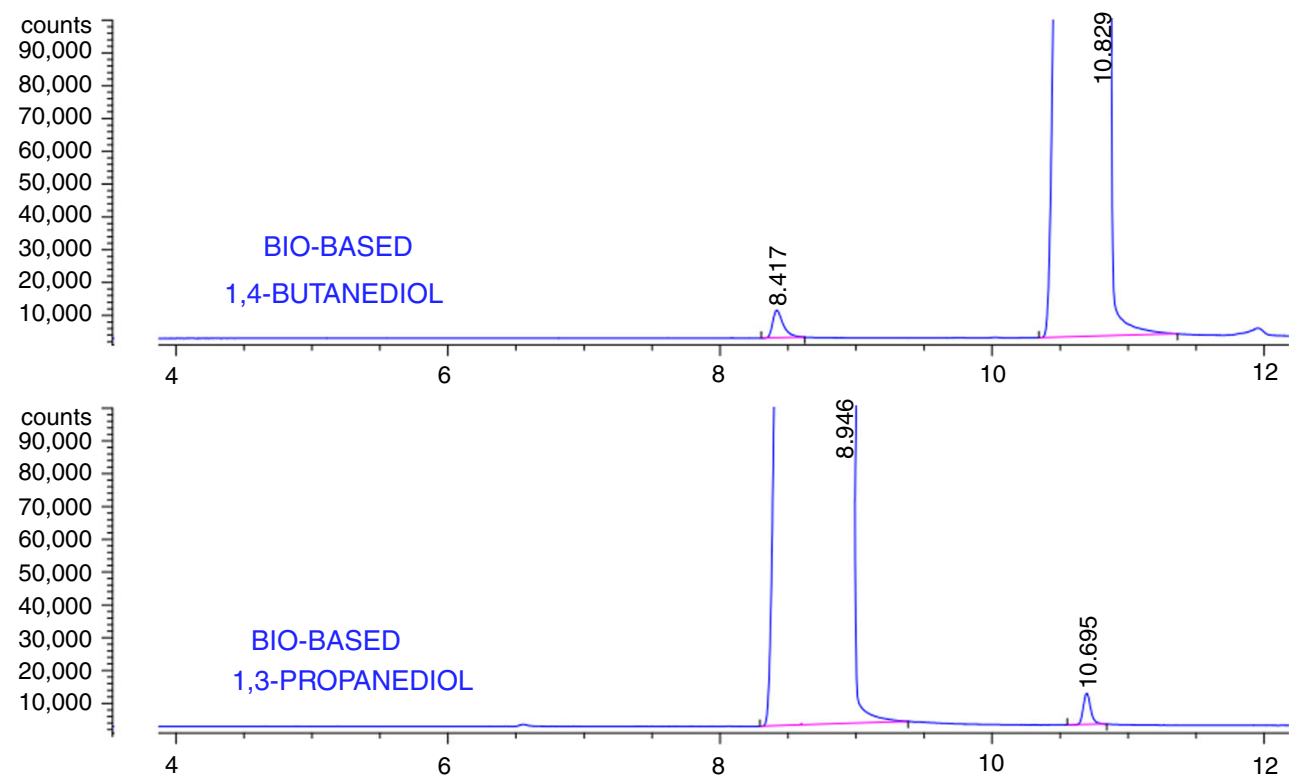

Fig. 8 GC chromatograms obtained during the chromatographic analysis of bio-based 1,3-propanediol and 1,4-butanediol

type machine. Results are averaged from ten independent measurements. The samples were $29 \mathrm{~mm}$ diameter and $12 \mathrm{~mm}$ height.

Density was determined by using an analytical balance RADWAG by hydrostatic method with methanol as an immersion medium, in accordance with ISO 2781. Measurements were taken at room temperature, and the results are averaged from five times for each prepared material.

Dynamic mechanical analysis (DMA) was investigated using DMA Q800 analyzer (TA Instruments) according to ASTM D6045. Measurements were taken in a temperature range from -100 to $+150{ }^{\circ} \mathrm{C}$ at an operating frequency of $1 \mathrm{~Hz}$ and heating rate of $4{ }^{\circ} \mathrm{C} \mathrm{min}^{-1}$. The samples were $2 \mathrm{~mm}$ thick, $10 \mathrm{~mm}$ wide and $40 \mathrm{~mm}$ long. The storage modulus, loss modulus and tan delta as a function of temperature was determined. DMA measurements were realized under air atmosphere.

Thermogravimetric Analysis (TG) of the prepared thermoplastic polyurethanes was performed using NETZSCH TG 209F3 analyzer. The samples were heated from 25 to $600{ }^{\circ} \mathrm{C}$ at a rate of $20{ }^{\circ} \mathrm{C} \mathrm{min}{ }^{-1}$. The measurements were realized under air atmosphere. The samples mass was around $5 \mathrm{mg}$. 


\section{Result and discussion}

\section{Chemical structure of petrochemical and bio-based glycols}

The FTIR spectra of all chain extenders are presented in Fig. 3 (petrochemical and bio-based 1,3-propanediol) and Fig. 4 (petrochemical and bio-based 1,4-butanediol). The all glycols displayed band at around $3300 \mathrm{~cm}^{-1}$, which is the characteristic of hydroxyl group stretching vibrations. The characteristic symmetric and asymmetric stretching vibration of $-\mathrm{CH}_{2}$ bond occurs at 2850 and $2940 \mathrm{~cm}^{-1}$, respectively. The peak at $1055 \mathrm{~cm}^{-1}$ is attributed to the stretching vibrations of $-\mathrm{C}-\mathrm{O}-$ bond. The insignificant differences are observed between the bio-based and petrochemical low molecular weight diols, which is connected with slight differences in the intensity of peaks (e.g., at $3300 \mathrm{~cm}^{-1}$ ). The ${ }^{1} \mathrm{H}$ NMR analysis of the glycols (Figs. 5, 6) also indicated that the slight differences are observed between different origin-based diols.

In order to confirm the presence of some contaminations (e.g., glycerol, which could be a by-product formed during the synthesis of bio-glycols) in the used glycols, the gas chromatography combined with a mass spectrometer was performed. The GC chromatograms of petrochemical and bio-based glycols, i.e., 1,3-propanediol and 1,4-butanediol, are presented in Figs. 7 and 8.

\section{Chemical structure, morphology and properties of poly(ester-urethane)s synthesized using petrochemical and bio-based glycols}

The FTIR analysis confirms the presence of characteristic chemical groups for the poly(ester-urethane)s (Figs. 9, 10). The all-obtained polyurethanes have very similar chemical structure. The band related to isocyanate groups (at $2250-2270 \mathrm{~cm}^{-1}$ ) was not observed, and this fact confirms the completion of the reaction between isocyanate and hydroxyl groups under applied conditions. The stretching vibrations of $-\mathrm{N}-\mathrm{H}$ (presented in the structure of urethane group) were registered at $3330 \mathrm{~cm}^{-1}$. The stretching vibrations of $\mathrm{C}=\mathrm{O}$ groups are presented in the range from 1680 to $1740 \mathrm{~cm}^{-1}$, and double peak is visible. The maximum of peak connected with the hydrogen-bonded carbonyl groups is observed at $1700 \mathrm{~cm}^{-1}$, while maximum at $1725 \mathrm{~cm}^{-1}$ is related to free carbonyl groups [46-48]. The band observed at $1595 \mathrm{~cm}^{-1}$ is attributed to the out-ofplane bending of $-\mathrm{NH}$. The band connected with the $\mathrm{CN}$ stretching vibrations is observed at $1529 \mathrm{~cm}^{-1}$. Bands in the range $1100-1220 \mathrm{~cm}^{-1}$ correspond to the stretching vibration of $\mathrm{C}(\mathrm{O}) \mathrm{O}-\mathrm{C}$ groups. In addition, intensive bands related to the stretching vibrations of $\mathrm{C}-\mathrm{H}$ groups

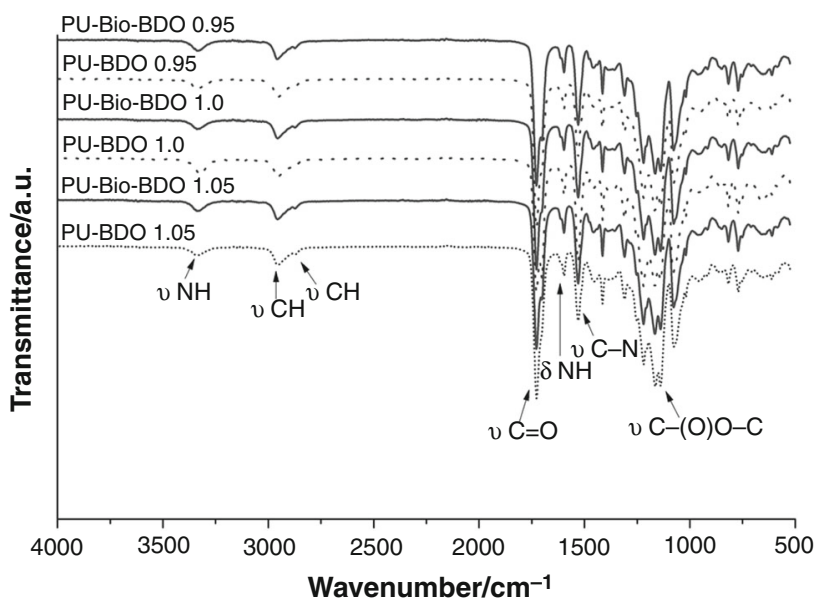

Fig. 9 FTIR spectra of polyurethanes prepared using 1,4-butanediol as a chain extender

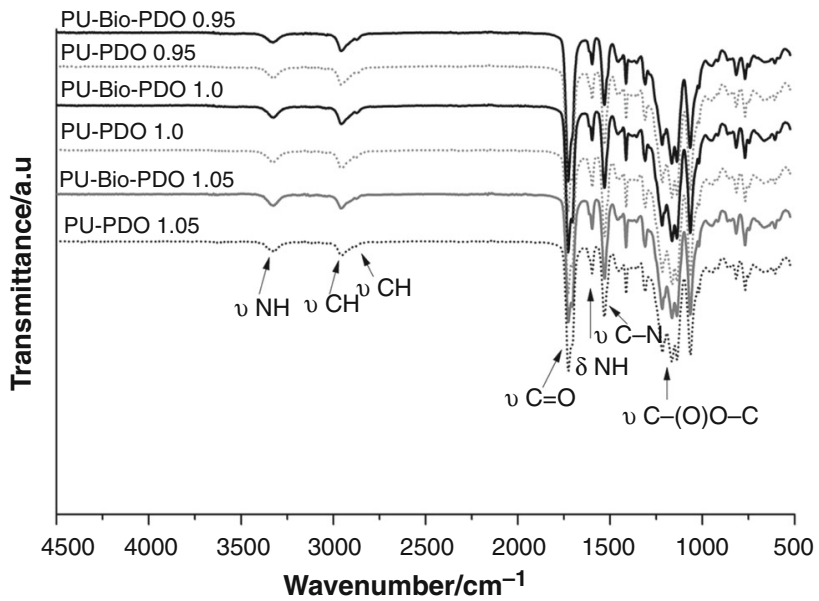

Fig. 10 FTIR spectra of polyurethanes prepared using 1,3-propanediol as a chain extender

(introduced into the structure of PUs by glycols and polyol) are observed at the wavenumbers from 2800 to $3000 \mathrm{~cm}^{-1}$, and these bands are connected with $\mathrm{C}-\mathrm{H}$ asymmetric stretching $\left(2956 \mathrm{~cm}^{-1}\right)$ and symmetric stretching $\left(2873 \mathrm{~cm}^{-1}\right)$. The deformation vibrations of the $\mathrm{C}-\mathrm{H}$ are observed at $1412 \mathrm{~cm}^{-1}$. The comparison of FTIR spectra for poly(ester-urethane)s obtained using 1,4-butanediol and 1,3-propanediol indicated that the both materials have very similar chemical structure, and the insignificant differences are observed.

The AFM morphology of selected poly(ester-urethane)s synthesized using petrochemical and bio-based 1,3propanediol or 1,4-butanediol is presented in Figs. 11 and 12, respectively. The dark regions corresponded to the regions reach in soft segments (SSs), while the light regions are related to the regions rich in hard segments (HSs) [49, 50]. Obtained results showed that prepared 

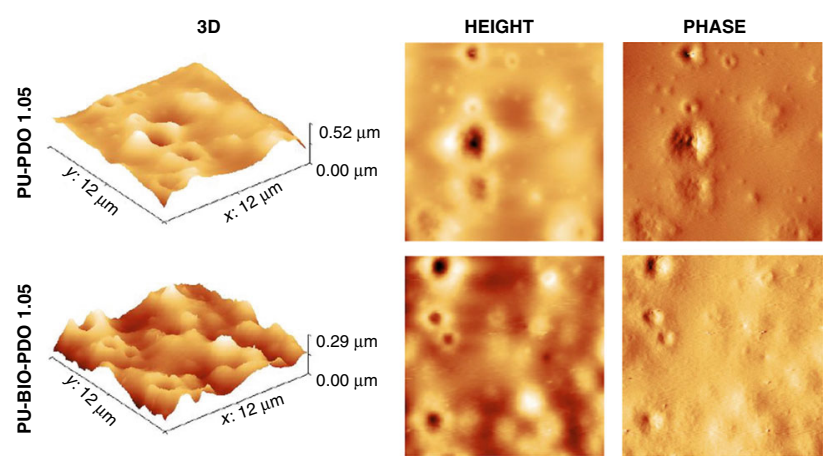

Fig. 11 Morphology of poly(ester-urethane)s synthesized using 1,3propanediol

polyurethanes have microphase-separated structure, but the higher degree of microphase separation is observed for the 1,4-butanediol polyurethanes. The origin of the low molecular weight diol did not affect the morphology of prepared materials.

Table 2 Tensile strength and elongation at break of obtained poly(ester-urethane)s

\begin{tabular}{lll}
\hline Material code & Tensile strength/MPa & Elongation at break/\% \\
\hline PU-Bio-BDO 0.95 & $20.8 \pm 3.8$ & $652 \pm 21$ \\
PU-Bio-BDO 1.0 & $25.5 \pm 4.3$ & $651 \pm 16$ \\
PU-Bio-BDO 1.05 & $23.2 \pm 2.5$ & $578 \pm 19$ \\
PU-BDO 0.95 & $17.4 \pm 2.8$ & $603 \pm 18$ \\
PU-BDO 1.0 & $27.2 \pm 3.1$ & $620 \pm 38$ \\
PU-BDO 1.05 & $26.9 \pm 2.3$ & $534 \pm 22$ \\
PU-Bio-PDO 0.95 & $12.2 \pm 4.7$ & $529 \pm 16$ \\
PU-Bio-PDO 1.0 & $14.4 \pm 1.3$ & $567 \pm 35$ \\
PU-Bio-PDO 1.05 & $25.4 \pm 2.6$ & $558 \pm 19$ \\
PU-PDO 0.95 & $18.3 \pm 3.2$ & $474 \pm 30$ \\
PU-PDO 1.0 & $30.4 \pm 2.9$ & $503 \pm 23$ \\
PU-PDO 1.05 & $35.7 \pm 4.2$ & $491 \pm 13$ \\
\hline
\end{tabular}

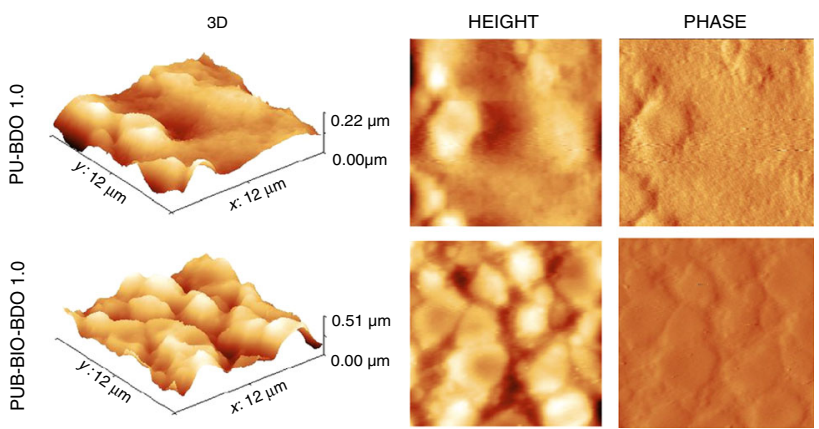

Fig. 12 Morphology of poly(ester-urethane)s synthesized using 1,3propanediol

The mechanical behavior of the poly(ester-urethane)s is strongly dependent on the molar ratio $[\mathrm{NCO}] /[\mathrm{OH}]$ applied during the prepolymer chains' extending step. Structural differences and probably presence of different contaminations in the applied petrochemical and bio-based diols also affect on the mechanical performance of the prepared PUs. Mentioned facts can cause differences in the chemical and physical cross-linking in obtained materials. The values of tensile strength and elongation at break are presented in Table 2.

The highest tensile strength (35.7 MPa) was observed for material coded as PU-PDO-1.05, which is connected with applying 1,3-propanediol as a chain extender. The materials prepared using petroleum-based 1,3-propanediol possess the higher tensile strength than materials obtained by using 1,4-butanediol as a chain extender. The polyurethanes obtained using bio-based chain extender, i.e., 1,3-propanediol, possess higher elongation at break and lower tensile strength, in comparison with the materials prepared using petrochemical 1,3-propanediol. The biobased glycols are produced from carbohydrates by fermentation process, and after the manufacturing process, the

Table 3 Hardness, rebound resilience and density of prepared poly(ester-urethane)s

\begin{tabular}{lllll}
\hline Code of material & Hardness $/{ }^{\circ}$ Sh A & Hardness $/{ }^{\circ}$ Sh D & Rebound resilience/\% & Density/g cm $^{-3}$ \\
\hline PU-Bio-BDO 0.95 & $80.4 \pm 0.4$ & $28.5 \pm 0.6$ & $53.5 \pm 0.8$ & $1.215 \pm 0.001$ \\
PU-Bio-BDO 1.0 & $82.2 \pm 0.5$ & $31.2 \pm 0.1$ & $58.4 \pm 1.7$ & $1.214 \pm 0.002$ \\
PU-Bio-BDO 1.05 & $80.9 \pm 0.3$ & $28.7 \pm 0.6$ & $57.1 \pm 0.6$ & $1.216 \pm 0.003$ \\
PU-BDO 0.95 & $78.2 \pm 0.5$ & $27.9 \pm 0.6$ & $51.3 \pm 0.7$ & $1.215 \pm 0.002$ \\
PU-BDO 1.0 & $80.0 \pm 0.5$ & $30.0 \pm 0.3$ & $56.6 \pm 1.1$ & $1.216 \pm 0.001$ \\
PU-BDO 1.05 & $81.2 \pm 0.3$ & $31.9 \pm 0.2$ & $55.6 \pm 0.6$ & $1.216 \pm 0.002$ \\
PU-Bio-PDO 0.95 & $79.7 \pm 0.6$ & $27.7 \pm 0.4$ & $49.0 \pm 1.0$ & $1.217 \pm 0.002$ \\
PU-Bio-PDO 1.0 & $80.5 \pm 0.3$ & $31.4 \pm 0.2$ & $54.7 \pm 0.8$ & $1.218 \pm 0.001$ \\
PU-Bio-PDO 1.05 & $82.9 \pm 0.4$ & $32.2 \pm 0.2$ & $57.4 \pm 0.8$ & $1.218 \pm 0.001$ \\
PU-PDO 0.95 & $78.8 \pm 0.5$ & $29.7 \pm 0.3$ & $48.0 \pm 1.0$ & $1.219 \pm 0.002$ \\
PU-PDO 1.0 & $80.7 \pm 0.5$ & $31.8 \pm 0.1$ & $52.3 \pm 0.7$ & $1.220 \pm 0.001$ \\
PU-PDO 1.05 & $82.6 \pm 0.5$ & $32.6 \pm 0.1$ & $56.1 \pm 0.3$ & $1.221 \pm 0.003$ \\
\hline
\end{tabular}


Table 4 Thermal stability of obtained poly(ester-urethane)s

\begin{tabular}{lllll}
\hline Code of material & $T_{5} /{ }^{\circ} \mathrm{C}$ & $T_{10} /{ }^{\circ} \mathrm{C}$ & $T_{30} /{ }^{\circ} \mathrm{C}$ & $T_{50} /{ }^{\circ} \mathrm{C}$ \\
\hline PU-Bio-BDO 0.95 & 315.9 & 328.4 & 370.9 & 388.4 \\
PU-Bio-BDO 1.0 & 325.2 & 337.7 & 395.2 & 415.2 \\
PU-Bio-BDO 1.05 & 325.7 & 338.2 & 393.2 & 413.2 \\
PU-BDO 0.95 & 313.3 & 328.3 & 368.3 & 385.8 \\
PU-BDO 1.0 & 321.3 & 336.3 & 393.8 & 413.8 \\
PU-BDO 1.05 & 317.7 & 330.2 & 385.2 & 405.2 \\
PU-Bio-PDO 0.95 & 316.7 & 329.2 & 374.3 & 394.3 \\
PU-Bio-PDO 1.0 & 320.4 & 332.9 & 390.4 & 412.9 \\
PU-Bio-PDO 1.05 & 323.6 & 333.6 & 393.6 & 413.6 \\
PU-PDO 0.95 & 315.5 & 328.0 & 370.5 & 390.6 \\
PU-PDO 1.0 & 323.2 & 335.7 & 395.7 & 415.7 \\
PU-PDO 1.05 & 322.7 & 332.7 & 395.2 & 415.2 \\
\hline
\end{tabular}

bio-based glycols contain some impurities. The highest elongation at break was observed for materials prepared using bio-based 1,4-butanediol as a chain extender. The materials obtained using petrochemical and bio-based 1,4butanediol possess tensile strength in the range from 17.4 to $27.2 \mathrm{MPa}$. The materials synthesized using both types of 1,4-butanediol at molar ratio $[\mathrm{NCO}] /[\mathrm{OH}]$ equal 1.0 during chain extending step showed the highest tensile strength in comparison to other materials, so molar ratio $[\mathrm{NCO}] /[\mathrm{OH}]$ equal 1.0 is optimum ratio for the preparation of polyurethanes using bio-based and petroleum-based 1,4-butanediol as a chain extender.

However, materials synthesized using bio-based and petroleum-based 1,3-propanediol as a chain extender showed that the optimum molar ratio $[\mathrm{NCO}] /[\mathrm{OH}]$ during the prepolymer chains' extending step is equal to 1.05 . These differences are due to the length of the chain of used glycols. In the case of the chain extenders about higher presence $\mathrm{CH}_{2}$ groups as a 1,4-butanediol, the final material is more elastic and exhibits low tensile strength and high elongation at break, due to the more symmetric structure. Some improvements in elongation at break were obtained by applying bio-based 1,4-butanediol or 1,3-propanediol, due to the origin their glycols, but these materials showed the lower tensile strength. Material prepared using bio-based chain extenders is more rigid: the PU-Bio-PDO possesses a tensile strength at approximately 12.2-25.4 MPa and elongation at break of $529-589 \%$ and PU-Bio-BDO having a tensile strength at $20.8-25.5 \mathrm{MPa}$ and elongation at break of $652-578 \%$, due to the lower intermolecular hydrogen bonding content and cross-link density in comparison with materials prepared using petrochemical-based glycols $(1,3-$ propanediol or 1,4-butanediol).

The presence of impurities (organic and inorganic compounds) in glycols is the one of possibilities responsible for the observed differences in tensile properties of obtained materials. The others are connected with the precision of polyurethanes preparing (e.g., dosing of chain extenders and degassing of reaction mixture), or maintaining similar conditions of samples preparation. The most important is the result obtained for optimum molar ratio [NCO]:[OH], which permits to obtain materials with the best mechanical performance. The mechanical properties are more sensitive for external factors (e.g., preparation of samples for test) than thermal properties, which are
Fig. 13 TG curves for the poly(ester-urethane)s obtained using 1,4-butanediol as a chain extender

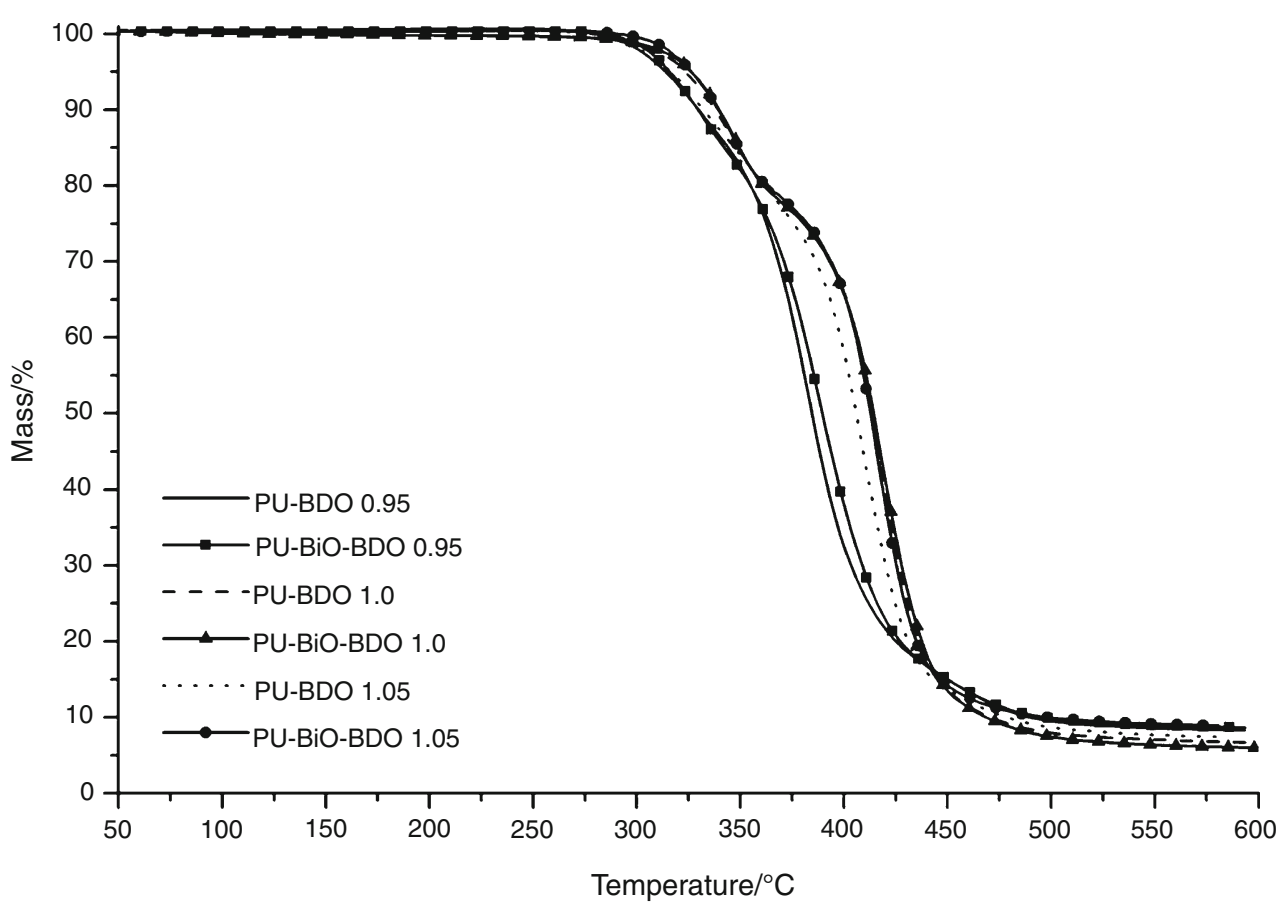


strongly affected by the chemical structure of materials. The thermal properties of obtained materials are very similar, so the chemical structure of obtained materials is also almost identical.

Table 3 summarizes the hardness, rebound resilience and density values for prepared poly(ester-urethane)s. The results depend on the type and origin of the chain extender. All materials possess hardness in the range from 78 to $82^{\circ} \mathrm{Sh} \mathrm{A}$ and rebound resilience in the range from 49 to $58 \%$. The hardness, rebound resilience and density of the materials obtained using bio-based chain extenders are similar to those determined for the PUs synthesized using petrochemical glycol. In the materials prepared using both types of 1,3-propanediol, the hardness and rebound resilience increase with increasing molar ratio $[\mathrm{NCO}] /[\mathrm{OH}]$ during prepolymer chains' extending step. The highest
Fig. 14 DTG curves for the poly(ester-urethane)s prepared by using 1,4-butanediol as a chain extender
Fig. 15 TG curves for the poly(ester-urethane)s obtained using 1,3-propanediol as a chain extender
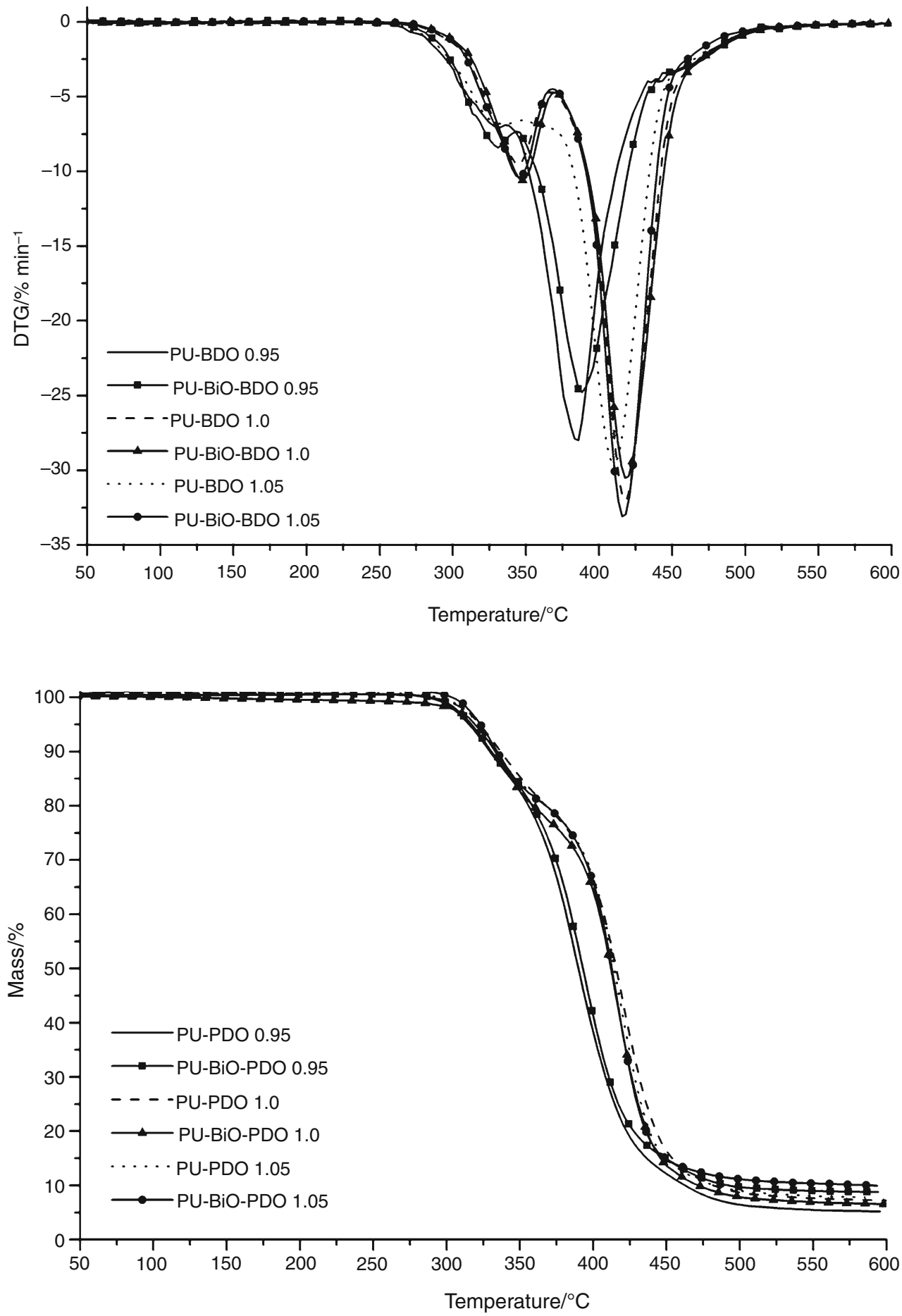
hardness and rebound resilience were observed for the material synthesized at the molar ratio $[\mathrm{NCO}] /[\mathrm{OH}]$ during prepolymer chains extending equal to 1.05 for PU-PDO. Materials prepared using bio-based and petroleum-based 1,4-butanediol showed the highest hardness and rebound resilience for the polymers synthesized at molar ratio $[\mathrm{NCO}] /[\mathrm{OH}]$ equal to 1.0 . The density of the prepared thermoplastic polyurethane is in the range from 1.214 to $1.1220 \mathrm{~g} \mathrm{~cm}^{-3}$, so the density is slightly affected by the type of chain extender.

The results of thermogravimetric analysis for the prepared materials are listed in Table 4. Figures 13 and 14 present TG curves of PU-BDO and PU-PDO materials (obtained using bio-based and petrochemical-based
Fig. 16 DTG curves for the poly(ester-urethane)s prepared using 1,3-propanediol as a chain extender
Fig. 17 Storage modulus as a function of temperature for the PUs prepared using 1,4butanediol as a chain extender
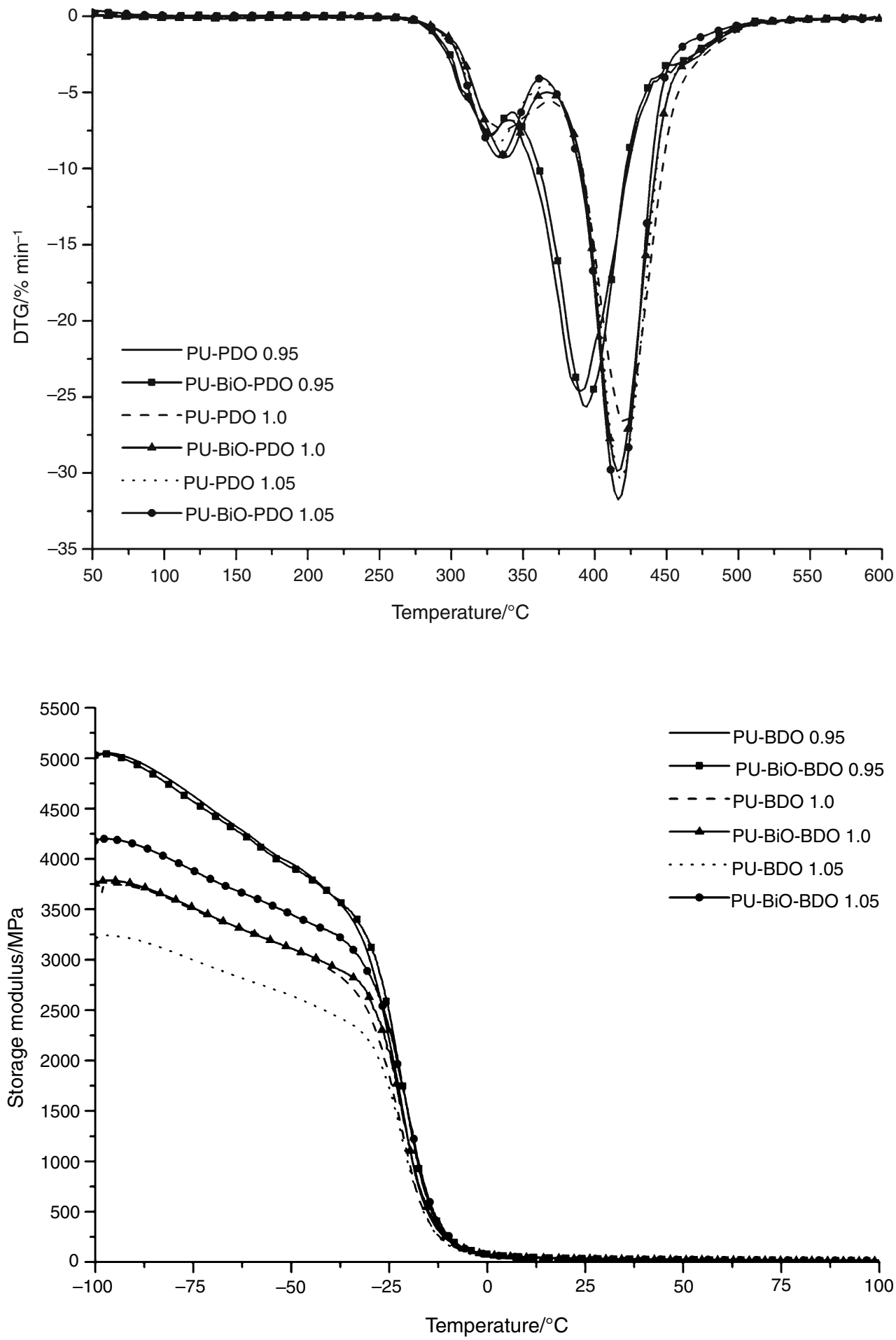
glycols). The results present that the increasing molar ratio $[\mathrm{NCO}] /[\mathrm{OH}]$ has a beneficial impact on the thermal stability of the prepared materials, because the higher temperatures of thermal decomposition are observed. This is resulted from the chemical contaminations, which are presented in small amounts in the bio-based glycols. The thermal stability of materials prepared using bio-based chain extender is very similar to their petrochemical analogues.

The onset temperature of the thermal degradation for each tested sample was approximately at $320{ }^{\circ} \mathrm{C}$, which is connected with the thermal decomposition of urethane bonds. As it can be seen from TG curves, the TPUs decompose quite intensively at $400-415{ }^{\circ} \mathrm{C}$ for the mate-
Fig. 18 Storage modulus as a function of temperature for the PUs prepared using 1,3propanediol as a chain extender
Fig. 19 Loss modulus as a function of temperature for the polyurethanes prepared using 1,4-butanediol as a chain extender
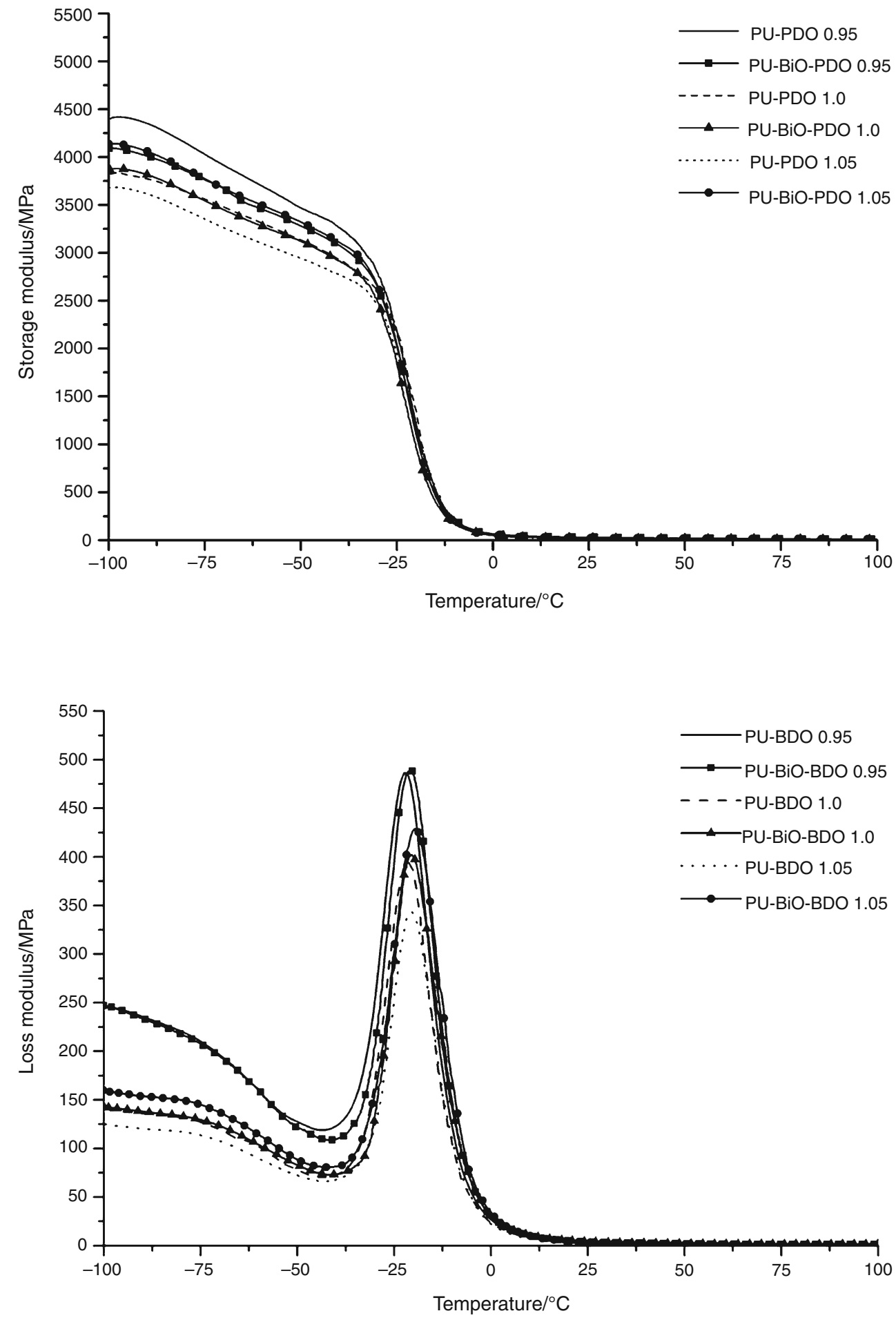
rial about molar ratio isocyanate group to hydroxyl group 1.0 and 1.05 during chain extending. Materials prepared at molar ratio $[\mathrm{NCO}] /[\mathrm{OH}]$ equal to 0.95 showed decomposition quite intensively at $380{ }^{\circ} \mathrm{C}$.

Figures 15 and 16 present the DTG curves for PU-BDO and PU-PDO materials, respectively. The thermal degradation of all materials occurs in two steps, so obtained materials have microphase-separated structure. The first peak is connected with thermal decomposition of the hard segments in the polyurethane, while the second peak is connected to the thermal decomposition of soft segments (ester bonds presented in the structure of POLIOS 55/20 polyol) [51].

The results of the dynamical mechanical analysis for the synthesized thermoplastic polyurethanes are shown in Figs. 17, 19 and 21 (for the PUs obtained using bio-based
Fig. 20 Loss modulus as a function of temperature for the PUs prepared using 1,3propanediol as a chain extender

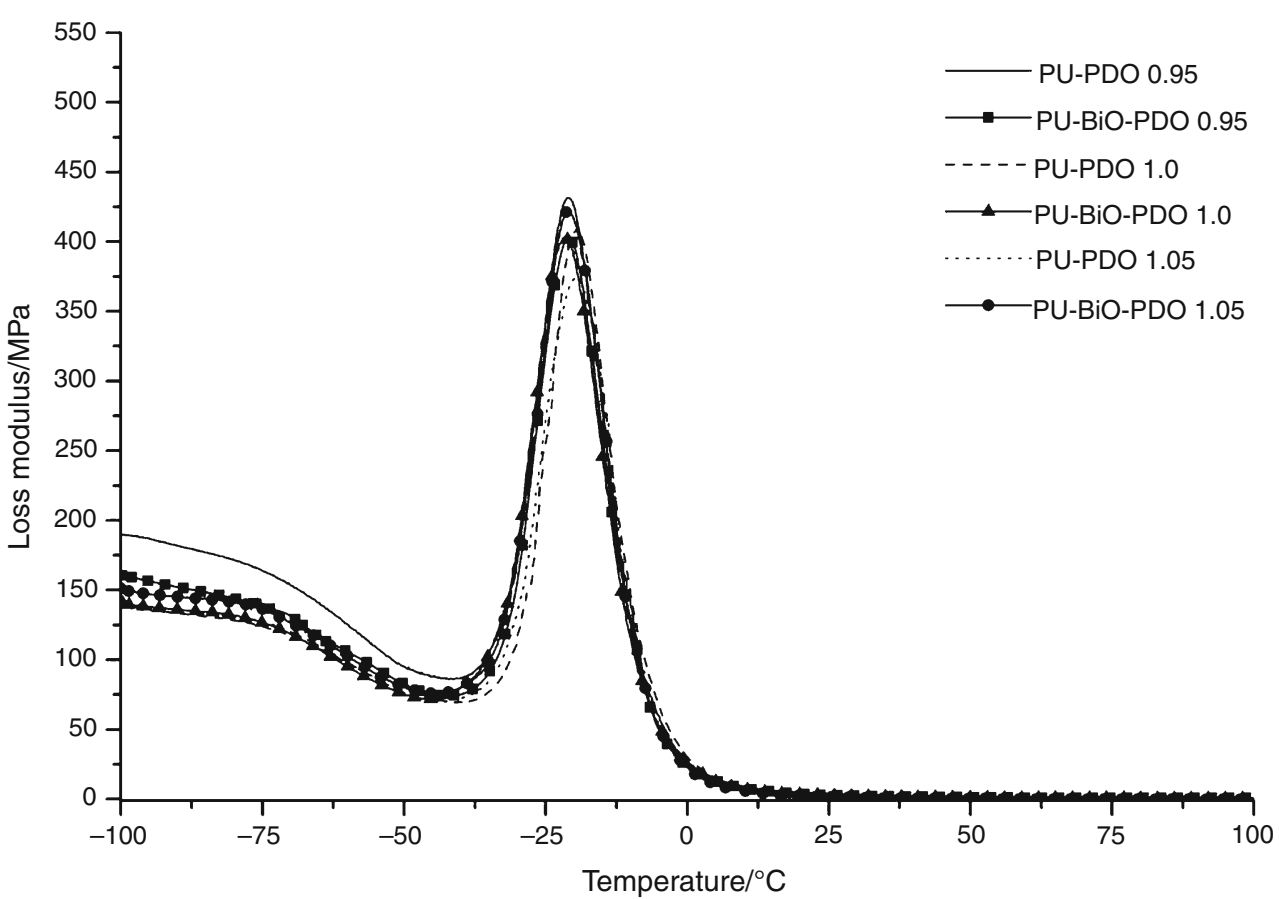

Fig. 21 Tan delta as a function of temperature for the polyurethane prepared using 1,4-butanediol as a chain extender

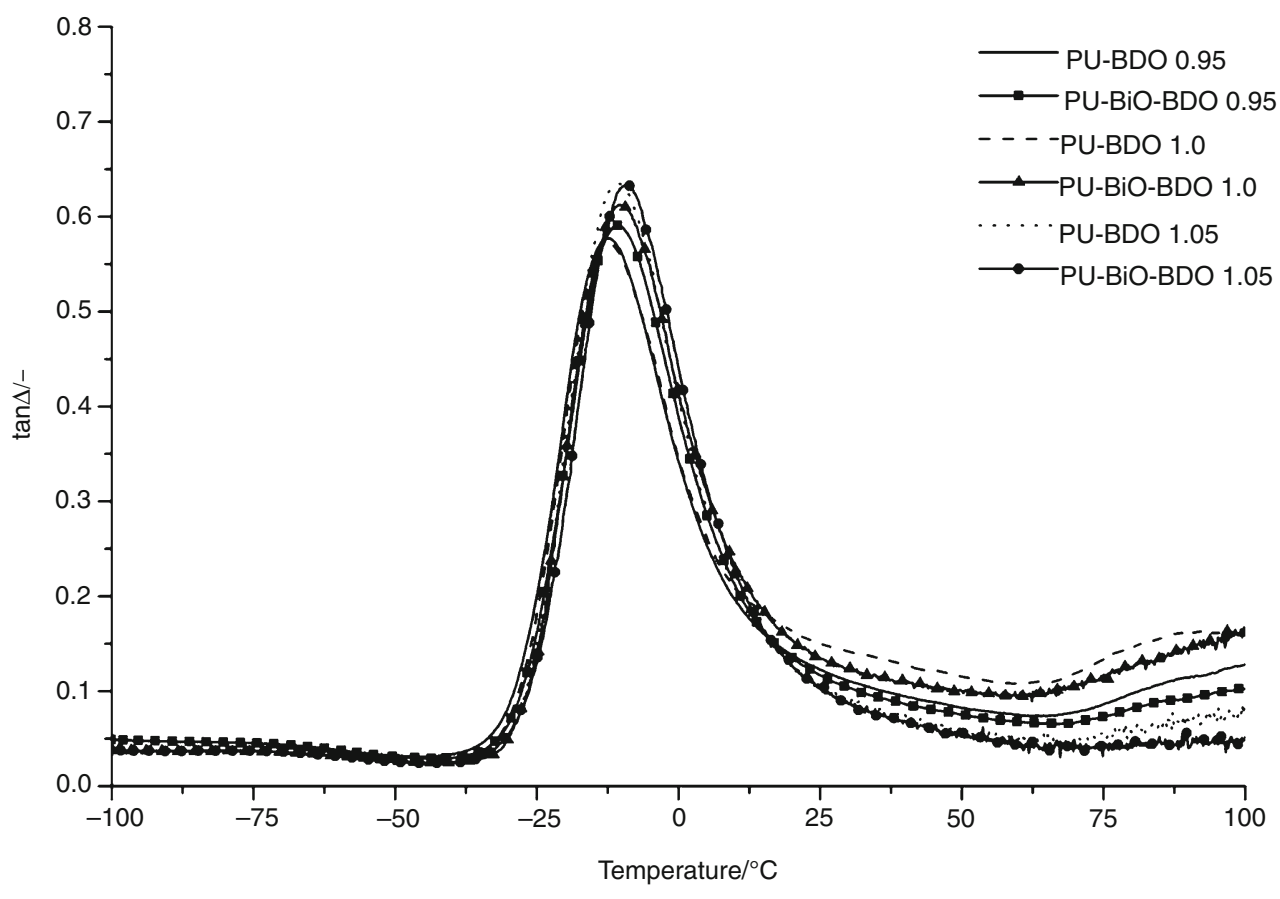


Fig. 22 Tan delta as a function of temperature for the PUs prepared using 1,3-propanediol as a chain extender

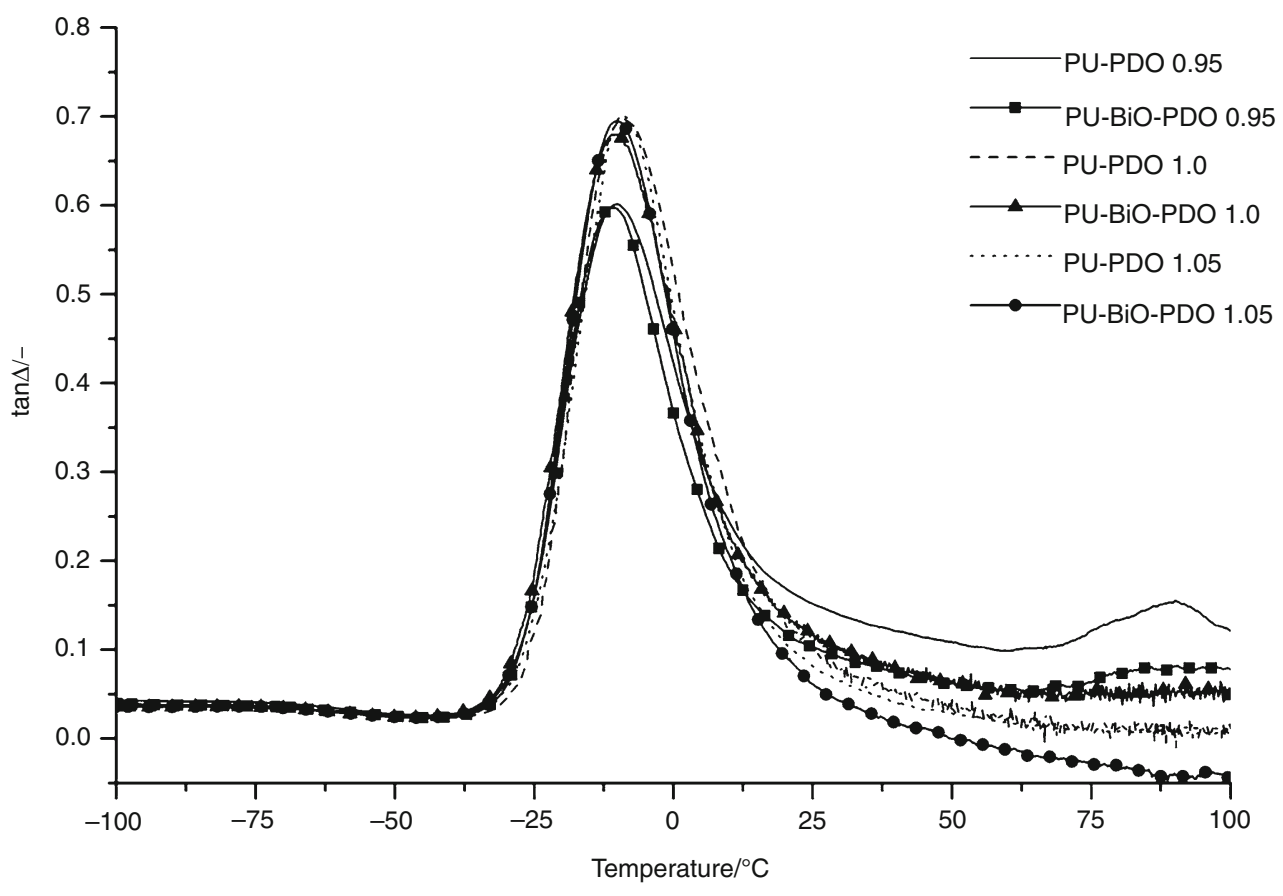

and petroleum-based 1,4-butanediol) and Figs. 18, 20 and 22 (for the PUs obtained using bio-based and petroleumbased 1,3-propanediol). The highest value to the storage modulus showed materials code PU-BDO 0.95 and PUBio-BDO 0.95, which suggests the higher stiffness of material, and this can be connected with the physical crosslinking due to the presence of higher hydrogen bonding. The storage modulus gradually decreases above $-25^{\circ} \mathrm{C}$ for all prepared materials, which is connected with the glass transition of the soft segments.

The value of the storage modulus is affected by the molar ratio $[\mathrm{NCO}] /[\mathrm{OH}]$ applied during the prepolymer chains extending, and the value of the storage modulus increases with decreasing molar ratio $[\mathrm{NCO}] /[\mathrm{OH}]$ for all prepared materials. Materials prepared using PDO or BioPDO as a chain extender showed smaller difference between the values of storage modulus than in the case of materials prepared using PDO and Bio-PDO as a chain extender.

Loss modulus of materials is in the range from 342 to $488 \mathrm{MPa}$ for PU-BDO and PU-Bio-BDO and from 374 to $431 \mathrm{MPa}$ for PU-PDO and PU-Bio-PDO. The lowest value of loss modulus was observed for the poly(ester-urethane)s synthesized at molar ratio $[\mathrm{NCO}] /[\mathrm{OH}]$ equal to 1.05 during the prepolymer chains' extending step. Loss modulus values increase with increasing molar ratio $[\mathrm{NCO}] /[\mathrm{OH}]$ during extending of the prepolymer chains.

Table 5 presents the glass transition temperatures of the soft segments ( $T_{\mathrm{g}}$ ss) for the prepared poly(ester-urethane)s. The $T_{\mathrm{g}}$ ss was determined as a temperature at which damping factor $(\tan \delta$ ) reaches maximum value, and
Table 5 Values of glass transition temperature of the soft segments ( $T_{\mathrm{g} \text { ss}}$ ) and values of damping factor $(\tan \delta$ ) for the obtained thermoplastic polyurethanes

\begin{tabular}{lcc}
\hline Code of material & $T_{\mathrm{g} \mathrm{ss}} \mathrm{DMA} /{ }^{\circ} \mathrm{C}$ & $\tan \delta$ \\
\hline PU-Bio-BDO 0.95 & -10.6 & 0.59 \\
PU-Bio-BDO 1.0 & -10.5 & 0.61 \\
PU-Bio-BDO 1.05 & -10.3 & 0.63 \\
PU-BDO 0.95 & -12.4 & 0.58 \\
PU-BDO 1.0 & -12.1 & 0.57 \\
PU-BDO 1.05 & -9.1 & 0.63 \\
PU-Bio-PDO 0.95 & -10.9 & 0.60 \\
PU-Bio-PDO 1.0 & -10.3 & 0.68 \\
PU-Bio-PDO 1.05 & -9.2 & 0.70 \\
PU-PDO 0.95 & -10.0 & 0.60 \\
PU-PDO 1.0 & -8.9 & 0.69 \\
PU-PDO 1.05 & -10.2 & 0.69 \\
\hline
\end{tabular}

this parameter is in the range from -10.3 to $-10.6{ }^{\circ} \mathrm{C}$ for PU-Bio-BDO, from -9.1 to $-12.4^{\circ} \mathrm{C}$ for PU-BDO, from -9.2 to $-10.9{ }^{\circ} \mathrm{C}$ for PU-Bio-PDO and from -8.9 to $-10.2{ }^{\circ} \mathrm{C}$ for PU-PDO. The poly(ester-urethane)s prepared using 1,4-butanediol as a chain extender possess lower glass transition temperature than materials obtained by using 1,3-propanediol as a chain extender.

The PU-PDO and PU-Bio-PDO possess higher maximum values $(0.60-0.70)$ of $\tan \delta$ than materials coded as PU-BDO or PU-Bio-BDO (0.57-0.63), so poly(ester-urethane)s prepared using petrochemical and bio-based propanediol have a higher ability for the damping of vibrations [46]. 


\section{Conclusions}

This work showed that using the different origin-based glycols (1,3-propanediol and 1,4-butanediol) as a chain extender allows to obtain poly(ester-urethane)s characterized by similar mechanical and thermal properties. The slight differences (in FTIR and ${ }^{1} \mathrm{H}$ NMR spectra) were observed between the bio-based and petrochemical glycol. Also, the chemical structure of poly(ester-urethane)s was slight different, when the different origin-based glycols were used. The highest tensile strength was observed for PUs synthesized using petrochemical-based 1,3-propanediol, while at the highest elongation and break, bio-based 1,4-butanediol was used as a chain extender. The values of mechanical properties and thermal properties are mostly affected by the molar ratio $[\mathrm{NCO}] /[\mathrm{OH}]$ during prepolymer chains' extending step and structural differences between used short organic diols. Materials prepared using 1,4-butanediol (biobased and petrochemical-based) as a chain extender showed the optimum ratio $[\mathrm{NCO}] /[\mathrm{OH}]$ equal to 1.0 , while materials obtained using 1,3-propanediol (different origin) showed the optimum ratio $[\mathrm{NCO}] /[\mathrm{OH}]$ equal to 1.05 during prepolymer chains' extending step. Therefore, it is possible to replace the petrochemical chain extenders by bio-based chain extender. As a result of this process, obtained materials will be more environmentally friendly and can exhibit slight improved thermal and mechanical properties, especially when the 1,4butanediol is used as a chain extender.

Open Access This article is distributed under the terms of the Creative Commons Attribution 4.0 International License (http://crea tivecommons.org/licenses/by/4.0/), which permits unrestricted use, distribution, and reproduction in any medium, provided you give appropriate credit to the original author(s) and the source, provide a link to the Creative Commons license, and indicate if changes were made.

\section{References}

1. Carriço C, Fraga T, Pasa V. Production and characterization of polyurethane foams from a simple mixture of castor oil, crude glycerol and untreated lignin as bio-based polyols. Eur Polym J. 2016;85:53-61.

2. Mizera K, Ryszkowska J. Polyurethane elastomers from polyols based on soybean oil with a different molar ratio. Polym Degrad Stab. 2016;132:21-31.

3. Ashrafizadeh H, Mertiny P, McDonald A. Evaluation of the effect of temperature on mechanical properties and wear resistance of polyurethane elastomers. Wear. 2016;368-369:26-38.

4. Alagia P, Choia Y, Seogb J, Hongs S. Efficient and quantitative chemical transformation of vegetable oils to polyols through a thiol-ene reaction for thermoplastic polyurethanes. Ind Crops Prod. 2016;87:78-88.

5. Malaki M, Hashemzadehb Y, Karevana M. Effect of nano-silica on the mechanical properties of acrylic polyurethane coatings. Prog Org Coat. 2016;101:477-85.
6. Demira M, Yilgorb I, Yilgorb E, Erman B. Electrospinning of polyurethane fibers. Polymer. 2002;43:3303-9.

7. Nangrejoa M, Bragmana F, Ahmadb Z, Stridea E, Edirisinghea M. Hot electrospinning of polyurethane fibres. Mater Lett. 2012;68:482-5.

8. Gabreil LP, Santos ME, Jardini AL, Bastos GN, Dias CG, Webster TJ, Maciel Filho R. Bio-based polyurethane for tissue engineering applications: how hydroxyapatite nanoparticles influence the structure, thermal and biological behavior of polyurethane composites. Nanomedicine. 2016;13:201-8.

9. Jing X, Mi HY, Huang HY, Turng LS. Shape memory thermoplastic polyurethane (TPU)/poly( $\varepsilon$-caprolactone) (PCL) blends as selfknotting sutures. J Mech Behav Biomed Mater. 2016;64:94-103.

10. Martínez-Abada A, González-Ausejob J, Lagaróna J, Cabedob L. Biodegradable poly(3-hydroxybutyrate-co-3-hydroxyvalerate)/ thermoplastic polyurethane blends with improved mechanical and barrier performance. Polym Degrad Stab. 2016;132:52-61.

11. Wirpsza Z. Polyurethanes-chemistry, technology and applications. Warsaw: WNT Press; 1993.

12. Prociak A, Rokicki G, Ryszkowska J. Polyurethane materials. Warsaw: PWN Press; 2014.

13. Datta J. Effect of glycols used as glycolysis agents on chemical structure and thermal stability of the produced glycolysates. J Therm Anal Calorim. 2012;109(2):517-20.

14. Datta J, Leszkowski K. Investigation of chemical stability of ether-urethane prepolymers. Polimery. 2008;53(2):115-9.

15. Jia L, Gong L, Ji W, Kan C. Synthesis of vegetable oil based polyol with cottonseed oil and sorbitol derived from natural source. Chin Chem Lett. 2011;22:1289-92.

16. Campanella A, Bonnaillie L, Wool R. Polyurethane foams from soyoil-based polyols. J Appl Polym Sci. 2009;112:2567-78.

17. Datta J, Głowińska E. Effect of hydroxylated soybean oil and biobased propanediol on the structure and thermal properties of synthesized bio-polyurethanes. Ind Crop Prod. 2014;61:84-91.

18. Rashmi B, Rusu D, Prashantha K, Lacrampe MF, Krawczak P. Development of bio-based thermoplastic polyurethanes formulations using corn-derived chain extender for reactive rotational molding. eXPRESS Polym Lett. 2013;7:852-62.

19. Głowińska E, Datta J. Structure, morphology and mechanical behaviour of novel bio-based polyurethane composites with microcrystalline cellulose. Cellulose. 2015;22:2471-81.

20. Włoch M, Datta J. Synthesis, structure and properties of poly(ester-urethane-urea)s synthesized using biobased diamine. J Renew Mater. 2016;4:72-7.

21. Calvo-Correas T, Santamaria-Echart A, Saralegi A, Martin L, Valea A, Corcuera M, Eceiza A. Thermally-responsive biopolyurethanes from a biobased diisocyanate. Eur Poym J. 2015;70:173-85.

22. Hojabri L, Kong X, Narine S. Fatty acid-derived diisocyanate and biobased polyurethane produced from vegetable oil: synthesis, polymerization, and characterization. Biomacromolecules. 2009;10:884-91.

23. Datta J, Włoch M. Progress in non-isocyanate polyurethanes synthesized from cyclic carbonate intermediates and di- or polyamines in the context of structure-properties relationship and from an environmental point of view. Polym Bull. 2016;73: 1459-96.

24. Rokicki G, Parzuchowski P, Mazurek M. Non-isocyanate polyurethanes: synthesis, properties, and applications. Polym Adv Technol. 2015;26:707-61.

25. Firdaus F. Chain extender on property relationships of polyurethane derived from soybean oil. World Acad Sci Eng Technol. 2011;5:179-82.

26. Prisacariu C, Scortanu E. Influence of the type of chain extender and urethane group content on the mechanical properties of polyurethane elastomers with flexible hard segments. High Perform Polym. 2011;23:308-13. 
27. Blackwell J, Nagarajan M, Hoitink T. Structure of polyurethane elastomers: effect of chain extender length on the structure of MDI/diol hard segments. Polymer. 1982;23:950-6.

28. DuPont Tate\&Lyle BioProducts. http://www.duponttateandlyle. com/zemea. Accessed 20 Oct 2016.

29. Erickson B, Nelson J, Winters P. Perspective on opportunities in industrial biotechnology in renewable chemicals. Biotechnol J. 2011;7:176-85.

30. Miller R. Susterra propanediol: a renewable and sustainable building block that delivers performance for the urethane industry. PU Mag. 2010;7:2-3.

31. DuPont Tate\&Lyle BioProducts. http://www.duponttateandlyle. com/susterra. Accessed 20 Oct 2016.

32. Obele C, Ogbobe O, Okonkwo I. Synthesis of 1, 3-propanediol from sorghum. Pak J Nutr. 2010;9:1058-60.

33. Myriant. http://www.myriant.com/media/press-kit-files/MyriantBioBDOBrochure-0613.pdf. Accessed 20 Oct 2016.

34. Genomatica. http://www.genomatica.com/news/press-releases/ basf-licenses-genomaticas-bdo-process/. Accessed 20 Oct 2016.

35. http://www.intratec.us/analysis/butanediol-e11a. Accessed 20 Oct 2016.

36. Drożdżyńska A, Leja K, Czaczyk K. Biotechnological production of 1,3-propanediol from crude glycerol. BioTechnologia: Biotechnol Comput Biol Bionanotechnol. 2011;92:92-100.

37. Yim H, Haselbeck R, Niu W, Pujol-Baxley C, Burgard A, Boldt J, Khandurina J, Trawick J, Osterhout R, Stephen R, Estadilla J, Teisan S, Schreyer H, Andrae S, Yang T, Lee S, Burk M, Van Dien S. Metabolic engineering of Escherichia coli for direct production of 1,4-butanediol. Nat Chem Biol. 2011;7:445-52.

38. Haasa T, Jaeger B, Weber R, Mitchell S, King C. New diol processes: 1,3-propanediol and 1,4-butanediol. Appl Catal A Gen. 2005;280:83-8.

39. Sisti L, Totaro G, Marchese P. PBS makes its entrance into the family of biobased plastics. In: Kalia S, Averous L, editors. Biodegradable and biobased polymers for environmental and biomedical applications. Hoboken: Wiley; 2016. p. 225-85.

40. Simola F, Scarsella M, De F. Process for producing 1,4-butanediol by hydrogenating dialkyl maleate in mixed liquid/vapor phase. US Patent 20140316146 A1, 23 Oct 2014.
41. Van Gorp JJ, Desalvo J, Miller R. Susterra ${ }^{\circledR}$ propanediol-renewability, sustainability and differentiating performance in urethane applications. http://www.duponttateandlyle.com/sites/ default/files/Susterra\%20white\%20paper\%20-\%20CPI\%202010. pdf. Accessed 25 Oct 2016.

42. Miller R, Durham R. Bio-based propanediol boosts preservative efficacy. http://www.duponttateandlyle.com/sites/default/files/ DuPontPCEuroApr12.pdf. Accessed 25 Oct 2016.

43. Liu D, Liu H, Sun Y, Lin R, Hao J. Method for producing other publications 1,3-propanediol using crude glycerol, a by-product from biodiesel production. US Patent 8486673, 2013.

44. Hwang HJ, Park JH, Kim JH, Kong KM, Kim JW, Park EW, Cho KM, Lee PC. Engineering of a butyraldehyde dehydrogenase of clostridium saccharoperbutylacetonicum to fit an engineered 1,4butanediol pathway in Escherichia coli. Biotechnol Bioeng. 2014; 7:1374-84.

45. Bibolet ER, Fernando GE, Shah SM. Renewable 1,4-butanediol CBE senior design project 2011. In: Penn Libraries University of Pennsylvania, 2011. http://repository.upenn.edu/cbe_sdr/22/. Accessed 27 April 2017.

46. Datta J, Głowińska E. Effect of hydroxylated soybean oil and biobased propanediol on the structure and thermal properties of synthesized bio-polyurethanes. Ind Crops Prod. 2014;61:84-91.

47. Puszka A, Kultys A. New thermoplastic polyurethane elastomers based on aliphatic diisocyanate. J Therm Anal Calorim. 2017;128(1):407-16.

48. Gurunathana T, Mohantya S, Nayaka S. Isocyanate terminated castor oil-based polyurethane prepolymer: synthesis and characterization. Prog Org Coat. 2015;80:39-48.

49. Rogulska M, Kultys A, Lubczak J. New thermoplastic polyurethane elastomers based on aliphatic-aromatic chain extenders with different content of sulfur atoms. J Therm Anal Calorim. 2015; 121:397-410.

50. Tocha J, Janik H, Dębowski M, Vancso GJ. Morphology of polyurethanes revisited by complementary AFM and TEM. J Macromol Sci Part B. 2002;B41:1291-304.

51. Kucińska-Lipka J, Gubańska I, Sienkiewicz M. Thermal and mechanical properties of polyurethanes modified with L-ascorbic acid. J Therm Anal Calorim. 2017;127(2):1631-8. 